\title{
Recurrent Moderate Hypoglycemia \\ Suppresses Brain-Derived Neurotrophic Factor Expression in the Prefrontal Cortex and Impairs Sensorimotor Gating in the Posthypoglycemic Period in Young Rats
}

\author{
Raghavendra Rao ${ }^{a, c}$ Kathleen Ennis ${ }^{a}$ Eugena P. Mitchell ${ }^{b}$ Phu V. Tran ${ }^{a, c}$ \\ Jonathan C. Gewirtz ${ }^{b, c}$ \\ ${ }^{a}$ Division of Neonatology, Department of Pediatrics, ${ }^{b}$ Department of Psychology, and ${ }^{c}$ Center for Neurobehavioral \\ Development, University of Minnesota, Minneapolis, Minn., USA
}

\section{Key Words}

Brain-derived neurotrophic factor - Prefrontal cortex .

Developing brain $\cdot$ Prepulse inhibition $\cdot$ Recurrent

hypoglycemia Young rat

\begin{abstract}
Recurrent hypoglycemia is common in infants and children. In developing rat models, recurrent moderate hypoglycemia leads to neuronal injury in the medial prefrontal cortex. To understand the effects beyond neuronal injury, 3-week-old male rats were subjected to 5 episodes of moderate hypoglycemia (blood glucose concentration, approx. $30 \mathrm{mg} / \mathrm{dl}$ for $90 \mathrm{~min}$ ) once daily from postnatal day 24 to 28 . Neuronal injury was determined using Fluoro-Jade B histochemistry on postnatal day 29. The effects on brain-derived neurotrophic factor (BDNF) and its cognate receptor, tyrosine kinase receptor B (TrkB) expression, which is critical for prefrontal cortex development, were determined on postnatal day 29 and at adulthood. The effects on prefrontal cortex-mediated function were determined by assessing the prepulse inhibition of the acoustic startle reflex on postnatal day 29 and 2
\end{abstract}

weeks later, and by testing for fear-potentiated startle at adulthood. Recurrent hypoglycemia led to neuronal injury confined primarily to the medial prefrontal cortex. BDNF/ TrkB expression in the prefrontal cortex was suppressed on postnatal day 29 and was accompanied by lower prepulse inhibition, suggesting impaired sensorimotor gating. Following the cessation of recurrent hypoglycemia, the prepulse inhibition had recovered at 2 weeks. BDNF/TrkB expression in the prefrontal cortex had normalized and fearpotentiated startle was intact at adulthood. Recurrent moderate hypoglycemia during development has significant adverse effects on the prefrontal cortex in the posthypoglycemic period.

(c) 2016 S. Karger AG, Basel

\section{Introduction}

Recurrent hypoglycemia is common in infants and children with congenital hyperinsulinism and insulin therapy for type 1 diabetes [1]. Recurrent severe hypoglycemia alters the brain structure and leads to cognitive def-

\section{KARGER}

E-Mail karger@karger.com

www.karger.com/dne
(C) 2016 S. Karger AG, Basel

0378-5866/16/0381-0074\$39.50/0
Raghavendra Rao, MD

Division of Neonatology, Department of Pediatrics

Mayo Mail Code 391, 420 Delaware Street, SE

Minneapolis, MN 55455 (USA)

E-Mail raghurao@umn.edu 
icits in these children [2-4]. Even mild and asymptomatic hypoglycemia is associated with attention and learning deficits, especially in the immediate posthypoglycemic period $[5,6]$.

Most hypoglycemic episodes during development are of mild-to-moderate severity and are not associated with neurological signs, such as altered consciousness or seizures. Studies in developing rats demonstrate that the medial prefrontal cortex (PFC) is highly vulnerable to injury during moderate hypoglycemia [7-10]. The effects beyond neuronal injury are not well characterized. In both humans and rats, the peak development of PFC occurs in the postnatal period $[11,12]$ and is characterized by increased glucose delivery to the region for supporting the energy requirement of synaptogenesis and neurotransmission [13]. Frequent disruptions in glucose supply due to recurrent hypoglycemia may compromise energy production in the PFC and alter its development and function.

The aim of the present study was to characterize the acute and long-term effects of recurrent moderate hypoglycemia on the expression of brain-derived neurotrophic factor (BDNF) and its receptors in the PFC and PFCregulated behaviors in 3-week-old rats. Rats of this age are used to model the effects of hypoglycemia in young children due to similarities in the stage of brain development and substrate utilization [7, 9, 11, 14, 15]. BDNF plays a critical role in the normal development of PFC [16-18]. It is a complex gene that generates multiple splice variants containing a common coding exon. BDNF-II, -IV and -VI variants are predominantly expressed in the cerebral cortex [19]. The binding of BDNF to the full-length isomer of tyrosine kinase receptor $\mathrm{B}$ $\left(\operatorname{TrkB}_{\mathrm{FL}}\right)$ promotes neuronal growth and survival [20]. Conversely, the binding of BDNF to the pan-neurotrophin p75 (p75 ${ }^{\mathrm{NTR}}$ ) receptor leads to cell cycle arrest, reduced neurite growth and apoptosis [20]. We have recently demonstrated that an acute episode of moderate hypoglycemia does not alter BDNF, TrkB and $\mathrm{p} 75^{\mathrm{NTR}}$ expression in the PFC of 3-week-old rats [14]. The effects of recurrent moderate hypoglycemia are not known. Other conditions that perturb energy metabolism in the postnatal period, such as recurrent hypoxia, are associated with suppressed BDNF expression in the PFC [21, 22].

We assessed the functional effects of recurrent hypoglycemia using behavioral tests of prepulse inhibition (PPI) of the acoustic startle reflex and fear conditioning. PPI measures sensorimotor gating: the ability of a weak sensory stimulus to inhibit the startle response to a sub- sequent intense stimulus. PPI is regulated by the medial PFC, hippocampus, nucleus accumbens, amygdala and pontine tegmental area [23] and is sensitive to imbalances in BDNF/TrkB expression in the PFC [24-27]. Fear was assessed as potentiation of the acoustic startle reflex (fear-potentiated startle, FPS) at adulthood. Two forms of Pavlovian fear-conditioning paradigms were used that differ only in the relative timing of presentation of the conditioned and unconditioned stimuli: 'trace' conditioning, which is dependent on the integrity of the PFC and dorsal hippocampus, and 'delay' conditioning, which is not. Both forms of fear conditioning are dependent on the amygdala [28].

\section{Materials and Methods}

\section{Animal Preparation}

The Institutional Animal Care and Use Committee at the University of Minnesota approved the study and its guidelines for the care and use of animals were followed. Pregnant SpragueDawley rats were purchased (Charles River Laboratories, Raleigh, N.C., USA) on gestational day 2 and allowed to deliver spontaneously. The litter size was culled to 8 ( 6 males and $2 \mathrm{fe}$ males per litter) on postnatal day 3 (P3). The pups were weaned on P21. Same-sex littermates were group-housed until P28 and then in same-sex pairs until adulthood. Only male rats $(n=64)$ were used due to the known sex-specific differences in postinsult BDNF expression and PPI regulation $[25,29]$. The rats were maintained under standard laboratory conditions with 12-hour light-dark cycles.

\section{Induction of Hypoglycemia}

The rats were randomly assigned to either the control group or the recurrent hypoglycemia group (RH group). To control for between- versus within-litter variance, equal numbers of rats in each litter were assigned to the two groups. The $\mathrm{RH}$ group was subjected to insulin-induced hypoglycemia from P24 to P28, once daily between 8.00 and 10.00 a.m. (total of 5 episodes). This model has been described previously [30]. Briefly, regular insulin (Novo Nordisk Inc., Clayton, N.C., USA) was injected in a dose of $10 \mathrm{IU} / \mathrm{kg}$, i.p., without prior fasting. The target blood glucose concentration was $20-40 \mathrm{mg} / \mathrm{dl}$, a value considered moderate hypoglycemia, as it is not associated with coma or seizures in rats of comparable age $[9,30]$. This severity and frequency of hypoglycemia is associated with cognitive and behavioral deficits in human infants and adults [31-33]. Littermates in the control group were injected with an equivalent volume of $0.9 \%$ saline (control group). Food was withheld (water available) in both groups and the ambient temperature was maintained at $34.0 \pm 1.0^{\circ} \mathrm{C}$ [30]. The blood glucose concentration was determined in tail vein samples every $15 \mathrm{~min}$. Hypoglycemia was terminated $120 \mathrm{~min}$ after the insulin administration by an injection of $10 \%$ dextrose $(200 \mathrm{mg} / \mathrm{kg}$, i.p.). The blood glucose concentration was determined $2 \mathrm{~h}$ later in randomly selected rats from each litter to confirm the resolution of hypoglycemia. The rats were left undisturbed until the day of additional experiments. 


\section{Behavioral Testing}

For both PPI and FPS, the rats were trained and tested in four identical $7.5 \times 8.5 \times 17.0 \mathrm{~cm}$ stabilimeter devices. Each stabilimeter consisted of a Plexiglas cage resting on four compression springs and located within a ventilated, sound-attenuating chamber. The ventilation fans elevated the background noise in the chamber to $65 \mathrm{~dB}$. Cage movement resulted in the displacement of a piezoelectric accelerometer (Model ACH-01; Measurement Specialties, Valley Forge, Pa., USA) attached to each cage. The voltage output from the accelerometer was filtered and amplified using a custom-built signal processor, digitized on a scale of arbitrary units (AU) ranging from 0 to 1,000 (National Instruments SCB100 and PCI-6071E boards) and recorded using MATLAB (The MathWorks, Natick, Mass., USA). Startle amplitude was defined as the peak accelerometer voltage during the first $200 \mathrm{~ms}$ after the onset of the startle stimulus. High-frequency speakers (Radio Shack Supertweeters, range: $5-40 \mathrm{kHz}$ ) located $10 \mathrm{~cm}$ from each cage delivered the startle stimuli, which were bursts of filtered white noise (low pass: $22 \mathrm{kHz}$, rise-decay $<5 \mathrm{~ms}$ ).

PPI tests were given on P29 (24 h after the last hypoglycemic episode) and repeated 2 weeks later on $\mathrm{P} 42(\mathrm{n}=16$ on each day) using previously reported methods $[34,35]$. After a 5-min acclimation period, 6 startle stimuli $(115 \mathrm{~dB}, 40 \mathrm{~ms})$ were presented at 30 -second intervals to habituate the startle response. Then, 15 prepulse-startle pairings were intermixed with 5 startle-alone trials, with a variable intertrial interval of $8-23 \mathrm{~s}$. For the prepulsestartle pairings, the onset of the prepulse $(68,71$ or $77 \mathrm{~dB})$ preceded the onset of the $115-\mathrm{dB}$ startle stimulus by $100 \mathrm{~ms}$. The percent PPI was calculated as follows: [(startle-alone) - (prepulse + startle) $] /$ startle-alone $\times 100$.

FPS training began on P56 (4 weeks after the termination of recurrent hypoglycemia). The foot shock unconditioned stimulus (US) was a 0.5 -second, 0.8 -mA constant current scrambled shock, delivered by a shock generator (SGS-004; BRS-LVE, Beltsville, Md., USA) through the four bars of the stabilimeter. The conditioned stimulus (CS) was a 7.5-second, 70- $\mathrm{dB}$ band-pass filtered noise with high and low cutoffs set at $4 \mathrm{kHz}$ and $24 \mathrm{~dB}$ per octave attenuation. The noise was delivered through a low-frequency speaker (Radio Shack Woofer, Model 40-1024A) situated $15 \mathrm{~cm}$ from the cage.

To measure the levels of baseline startle, the rats $(n=16)$ underwent 2 days of startle testing prior to fear conditioning. On each day, after a 5-min acclimation period, they were presented with 40 startle stimuli (20 each at 95 and $105 \mathrm{~dB}$ intermixed pseudorandomly; interstimulus interval of $30 \mathrm{~s}$ ). For fear conditioning on days 3-5, after a 5-min acclimation period, different groups of rats were exposed to delay or trace fear conditioning. For delay fear conditioning, the rats were presented with 12 trials consisting of the 7.5-second tone CS co-terminating with the 0.5 -second shock US (variable intertrial interval of $90-180 \mathrm{~s}$ ). For trace fear conditioning, the onset of the 0.5 -second shock US occurred $3 \mathrm{~s}$ after the offset of a 4-second tone CS. Hence, the interval between the onsets of the 2 stimuli in the two conditioning paradigms was the same. FPS was tested on day 6 (P62; young adulthood). After a 5-min acclimation period, 30 startle stimuli (95 and $105 \mathrm{~dB}$ ) were followed by 10 startle stimuli presented $3.5 \mathrm{~s}$ after the onset of the CS and 10 presented $7.0 \mathrm{~s}$ after CS onset (at the time the shock would have been presented during training). The average potentiation across these two time points provides a reliable mea- sure of FPS. These CS-startle stimulus pairings were intermixed with 10 additional startle stimulus presentations in the absence of the CS. FPS was calculated as follows: [(CS + startle) - (startlealone)]/startle-alone $\times 100 \%$.

\section{Tissue Preparation}

The rats were killed on either P29, $24 \mathrm{~h}$ after the last hypoglycemic episode, or P65 (young adulthood) using sodium pentobarbital (100 mg/kg, i.p.). The brain was removed within $10 \mathrm{~min}$ of pentobarbital administration and the PFC was dissected on ice, flash-frozen using liquid nitrogen and stored at $-80^{\circ} \mathrm{C}$. The rats used for histochemistry underwent in situ perfusion-fixation before brain removal. Serial $20-\mu \mathrm{m}$ coronal brain sections were obtained using a cryostat, mounted on glass slides and stored at $-20^{\circ} \mathrm{C}$ until histochemistry.

\section{Assessment of Regional Injury}

Regional injury was determined on P29 using Fluoro-Jade B (FJB) histochemistry using published methods $(\mathrm{n}=8)[7,8]$. Pilot studies demonstrated that injury was primarily limited to rostral brain sections $(3.5-8 \mathrm{~mm}$ anterior to the zero plane of the stereotaxic coordinates at P21). Digital photomicrographs of 4-6 sections from this region were collected and all FJB-stained cells in the brain sections were manually counted in a blinded fashion $[7,8]$.

\section{Quantitative RT-PCR}

The transcript expression of BDNF ( $B d n f$; variants II, IV and VI), TrkB (Ntrk2), p75 ${ }^{\text {NTR }}$ (Ngfr) and the downstream targets of $\mathrm{BDNF} /$ TrkB signaling, early growth response-1 and -2 (Egrl and Egr2), 3-hydroxy-3-methylglutaryl-CoA reductase ( $\mathrm{Hmgcr}$ ) and profilin-1 and -2 ( $P f n 1$ and $P f n 2$ ) that regulate brain development and plasticity [36-38] was determined using previously described methods ( $n=6-10$ on P29 and P65) $[8,14]$. Each sample was assayed in duplicate and normalized against ribosomal protein S18.

\section{Western Blot Analysis}

$\mathrm{BDNF}$ and $\operatorname{TrkB}\left(\operatorname{TrkB}_{\mathrm{FL}}\right.$ and truncated TrkB isomers, $\left.\operatorname{TrkB}_{\mathrm{TR}}\right)$ protein levels were determined using primary antibodies against BDNF (1:1,000; Abcam, Cambridge, Mass., USA), TrkB (1:1,000; Cell Signaling, Danvers, Mass., USA) and $\beta$-actin (1:5,000; Sigma Chemical Co., St. Louis, Mo., USA), and fluorescent secondary antibodies (1:2,500; Life Technologies, Grand Island, N.Y., USA) using published methods ( $\mathrm{n}=4-6$ on P29 and $\mathrm{P} 65)$ [8]. The target protein intensity relative to $\beta$-actin was determined.

\section{Data Analysis}

The effects of recurrent hypoglycemia on neuronal injury, mRNA and protein expression, and trace and delay fear conditioning were determined using unpaired $t$ tests. The acute and long-term effects on PPI were determined using ANOVA. To assess for any differences in startle between the groups, an analysis of startle magnitude during the startle habituation period ('baseline' startle) was conducted. PPI was evaluated using a $2 \times 2 \times 3$ (group $\times$ age $\times$ prepulse intensity) mixed-model ANOVA, with age and prepulse intensity as repeated measures, followed by post hoc comparisons using Tukey's HSD test. Data are presented as means \pm SEM. Statistical significance was set at $\mathrm{p}<0.05$. 
Fig. 1. Neuronal injury after recurrent hypoglycemia in young rats. Three-week-old male rats were subjected to insulin-induced moderate hypoglycemia once daily from P24 to P28. Littermates in the control group were injected with equal volumes of normal saline. Coronal brain sections of the PFC collected $24 \mathrm{~h}$ after the last hypoglycemic episode from representative rats from the control group (a) and the $\mathrm{RH}$ group (b) and stained for injured cells using FJB histochemistry demonstrate FJBpositive cells in the medial PFC in the $\mathrm{RH}$ group (arrows in b). Scale bar $=100 \mu \mathrm{m}$.
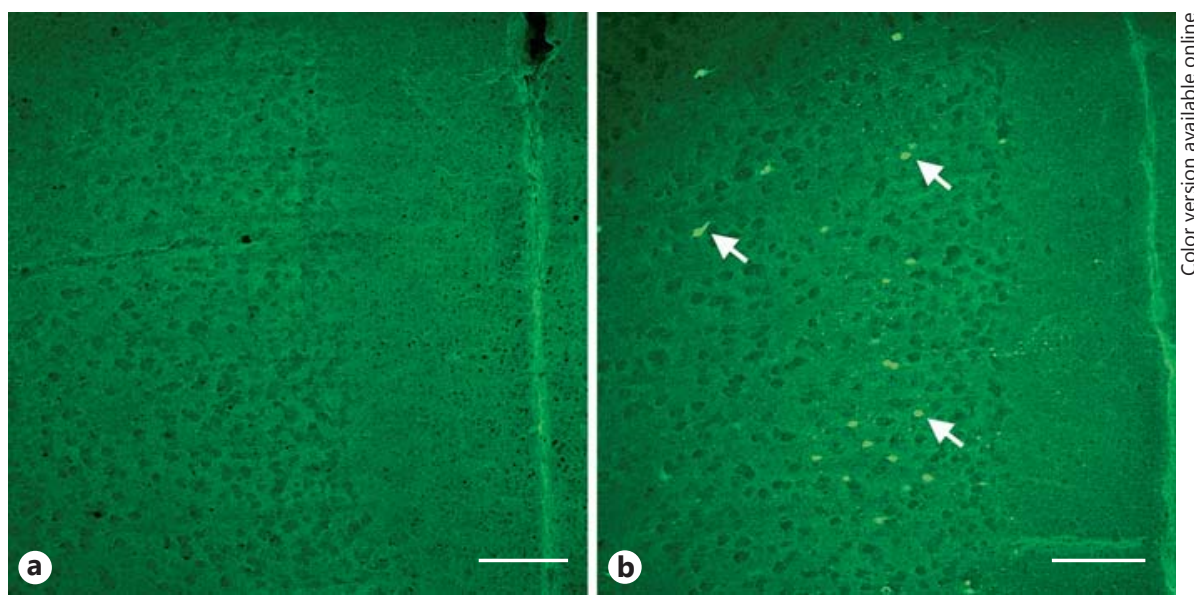

Table 1. Blood glucose concentrations $(\mathrm{mg} / \mathrm{dl})$ in the control and $\mathrm{RH}$ groups

\begin{tabular}{lll}
\hline Postnatal day & Control group & RH group \\
\hline 24 & $137 \pm 2$ & $33 \pm 2^{*}$ \\
25 & $129 \pm 3$ & $35 \pm 4^{*}$ \\
26 & $133 \pm 4$ & $21 \pm 2^{*}$ \\
27 & $125 \pm 9$ & $21 \pm 4^{*}$ \\
28 & $127 \pm 3$ & $30 \pm 2^{*}$ \\
\hline Overall & $132 \pm 1$ & $31 \pm 1^{*}$ \\
\hline
\end{tabular}

Values are means \pm SEM. Three-week-old rats were subjected to insulin-induced hypoglycemia once daily from P24 to P28. Littermates in the control group were injected with equal volumes of normal saline. Blood glucose concentration was measured in the tail vein sample every $15 \mathrm{~min}$ during the $120 \mathrm{~min}$ of observation ( $\mathrm{n}=31-84$ blood samples from a total of 64 rats on each day). $* \mathrm{p}<0.001$ vs. control group.

\section{Results}

\section{Blood Glucose Concentration}

The target blood glucose concentration $(20-40 \mathrm{mg} / \mathrm{dl})$ was reached within $30 \mathrm{~min}$ of insulin administration in the $\mathrm{RH}$ group and was maintained in this range until the $10 \%$ dextrose administration at $120 \mathrm{~min}$ (90 min of hypoglycemia) on each of the 5 days (table 1). The animals were less active, but conscious and seizure-free during the period of hypoglycemia. The blood glucose concentration $2 \mathrm{~h}$ after hypoglycemia was comparable in the two groups (control group, $139 \pm 7 \mathrm{mg} / \mathrm{dl}$; RH group, $130 \pm 31 \mathrm{mg} / \mathrm{dl}$ ). Recur-
Table 2. Acute and long-term effects of recurrent hypoglycemia on the transcript expression downstream of BDNF/TrkB signaling in the PFC of young rats

\begin{tabular}{llllll}
\hline Transcript & P29 & & & P65 \\
\cline { 2 - 3 } \cline { 6 - 7 } & $\begin{array}{l}\text { control } \\
\text { group }\end{array}$ & $\begin{array}{l}\text { RH } \\
\text { group }\end{array}$ & & $\begin{array}{l}\text { control } \\
\text { group }\end{array}$ & $\begin{array}{l}\text { RH } \\
\text { group }\end{array}$ \\
\hline Egr1 & $1.00 \pm 0.04$ & $0.81 \pm 0.05^{*}$ & & $1.00 \pm 0.05$ & $0.99 \pm 0.08$ \\
Egr2 & $1.00 \pm 0.12$ & $0.66 \pm 0.10^{*}$ & & $1.00 \pm 0.12$ & $1.23 \pm 0.15$ \\
Hmgcr & $1.00 \pm 0.05$ & $0.84 \pm 0.04^{*}$ & & $1.00 \pm 0.10$ & $1.12 \pm 0.14$ \\
Pfn1 & $1.00 \pm 0.07$ & $0.78 \pm 0.06^{*}$ & & $1.00 \pm 0.06$ & $0.90 \pm 0.05$ \\
Pfn2 & $1.00 \pm 0.09$ & $0.77 \pm 0.05^{*}$ & & $1.00 \pm 0.08$ & $0.79 \pm 0.07$ \\
\hline
\end{tabular}

Values are means \pm SEM normalized to the control group at each age $(n=6-10)$. Three-week-old rats were subjected to insulin-induced moderate hypoglycemia once daily from P24 to P28. Littermates in the control group were injected with equal volumes of normal saline. Brain tissue was harvested on either P29 or P65 for determining transcript expression in the PFC. ${ }^{*} \mathrm{p}<0.05$ vs. control group of corresponding age (unpaired t tests).

rent hypoglycemia did not affect body weight on either P29 (control group, $106 \pm 2$ g; RH group, $109 \pm 2$ g) or P65 (control group, $345 \pm 8 \mathrm{~g}$; RH group, $359 \pm 11 \mathrm{~g}$ ).

\section{Neuronal Injury after Hypoglycemia}

At $24 \mathrm{~h}$ after hypoglycemia, FJB-positive cells, indicative of cell injury, were present in the $\mathrm{RH}$ group but not in the control group (FJB-positive cells/brain section: control group, $0 \pm 0$; RH group, $86 \pm 21$, p $<0.01$ ). FJB-positive cells were visualized primarily in the cingulate and orbital regions of the medial PFC ( $46 \%$ of all FJB-positive cells; fig. 1) and layers III and IV of the 


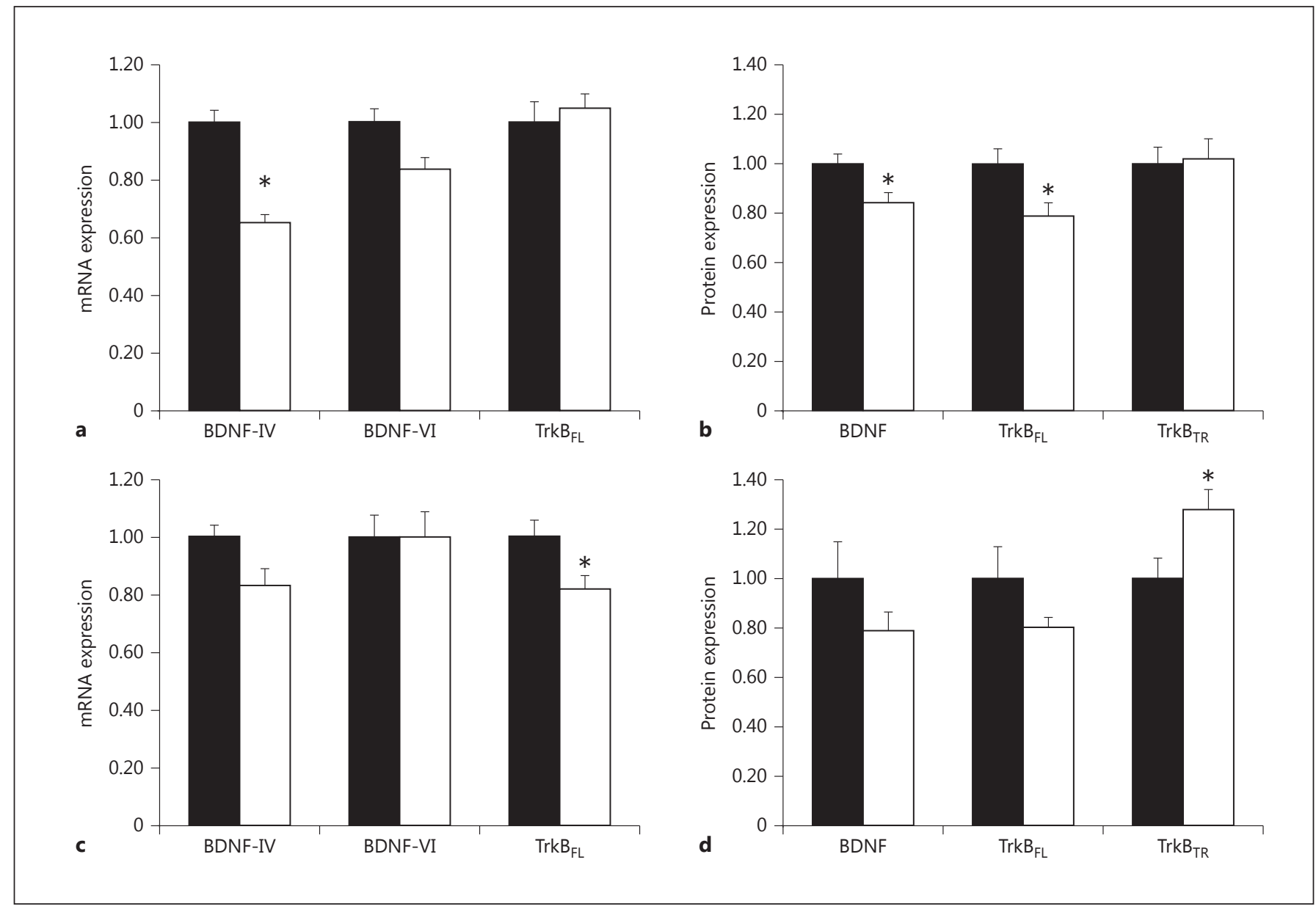

Fig. 2. Acute and long-term effects of recurrent hypoglycemia on BDNF and TrkB mRNA and protein expressions in the PFC of young rats. Three-week-old male rats were subjected to insulininduced moderate hypoglycemia once daily from P24 to P28. Littermates in the control group were injected with equal volumes of normal saline. BDNF and TrkB transcript and protein expression in the PFC was determined $24 \mathrm{~h}$ after hypoglycemia (a, b) and at adulthood (c, d). Black bars = Control group; white bars $=\mathrm{RH}$ group. Values are means \pm SEM normalized to the control group ( $\mathrm{n}=6-10$ for mRNA expression; $\mathrm{n}=4-6$ for protein expression). $* \mathrm{p}<0.05$ vs. control group (unpaired t tests). parietal (35\%) and temporal (19\%) cortices (data not shown). FJB-positive cells were absent in other brain regions.

\section{Effects of Recurrent Hypoglycemia on BDNF}

Expression in the PFC

On P29, Bdnf-IV expression was 35\% lower in the $\mathrm{RH}$ group ( $<<0.001$; fig. 2a). Bdnf-II (control group, $1.00 \pm$ 0.08 ; RH group, $0.89 \pm 0.10$ ), and $B d n f-V I$ (fig. $2 \mathrm{a}$ ) expression was not altered. The BDNF protein level was $16 \%$ lower in the RH group ( $\mathrm{p}=0.03$; fig. $2 \mathrm{~b}$ ) and was accompanied by a $21 \%$ lower $\operatorname{TrkB} \mathrm{FL}_{\mathrm{FL}}$ protein level $(\mathrm{p}=0.03$; fig. $2 \mathrm{~b}$ ). The $\operatorname{TrkB}_{\mathrm{TR}}$ protein level was not altered (fig. $2 \mathrm{~b}$ ).
The expression of downstream targets of BDNF/TrkB signaling, Erg1, Erg2, Hmgcr, Pfn1 and Pfn2 was 16-34\% lower in the RH group ( $\mathrm{p}<0.05$; table 2 ).

On P65, the expression of Bdnf-II (control group, 1.00 \pm 0.10 ; RH group, $1.03 \pm 0.12), B d n f-I V$ and $B d n f-V I$ (fig. 2c), as well as BDNF protein (fig. 2d), was comparable in the control and $\mathrm{RH}$ groups. The TrkB $\mathrm{FL}_{\mathrm{FL}}$ protein level was not altered (fig. $2 \mathrm{~d}$ ), while the $\operatorname{TrkB}_{\mathrm{TR}}$ protein level was $28 \%$ higher ( $<<0.05$; fig. $2 \mathrm{~d}$ ) in the RH group. Erg1, Erg2, Hmgcr, Pfn1 and Pfn2 expression was not altered (table 2). Recurrent hypoglycemia did not alter p $75^{\mathrm{NTR}}$ receptor mRNA (Ngfr) expression at either age (data not shown). 
Effects of Recurrent Hypoglycemia on Behavioral Tests

Baseline startle amplitude was comparable in the two groups on P29 (control group, $2.5 \pm 0.2 \mathrm{AU}$; RH group, $2.7 \pm 0.2 \mathrm{AU}$ ) and $\mathrm{P} 42$ (control group, $2.1 \pm 0.3 \mathrm{AU} ; \mathrm{RH}$ group, $2.0 \pm 0.2 \mathrm{AU}$ ). PPI was stronger on $\mathrm{P} 42$ than on P29 in both groups (fig. 3 ). There were significant main effects of group $(\mathrm{F}=4.2, \mathrm{p}<0.05)$, age at test $(\mathrm{F}=66.2, \mathrm{p}<0.01)$ and group $\times$ age interaction $(\mathrm{F}=4.9, \mathrm{p}<0.05)$ on PPI. As expected, PPI was positively related to prepulse intensity $(\mathrm{F}=17.3, \mathrm{p}<0.01)$, but there were no significant interactions as a function of this factor $(\mathrm{F}<1.3)$. PPI was significantly lower in the $\mathrm{RH}$ group compared with the control group at P29, and similar in both groups at $\mathrm{P} 42$ ( $\mathrm{p}<0.05$ for all, Tukey's HSD tests; fig. 3). Recurrent hypoglycemia did not significantly alter the magnitude of trace and delay FPS on P65 (online supplementary figure 1, see www. karger.com/doi/10.1159/000442878).

\section{Discussion}

Recurrent moderate hypoglycemia led to injury in the medial PFC, as evident by the presence of FJB-positive cells in the region. Although not characterized in the present study, previous hypoglycemia studies in developing and adult rats have established that FJB-positive cells represent neuronal injury $[7-9,14,39]$. As in those studies, FJB-positive cells were primarily seen in the cingulate and orbital regions of the PFC, highlighting the vulnerability of the medial PFC to injury during moderate hypoglycemia. The reasons for the increased vulnerability are not well understood. In adult humans, acute hypoglycemia leads to neuronal activation in the medial PFC that fails to normalize after the correction of hypoglycemia $[40,41]$. Persistent activation in the setting of neuroglycopenia and compromised energy metabolism [42-44] may have predisposed these neurons to injury.

In addition to neuronal injury, recurrent hypoglycemia suppressed BDNF and TrkB expression in the PFC. Although pentobarbital is known to attenuate BDNF and TrkB mRNA induction in the brain regions $[45,46]$, the short interval ( $<10 \mathrm{~min})$ between pentobarbital administration and tissue collection rules out this possibility in the present study. It takes several hours for BDNF and TrkB suppression to occur after pentobarbital administration or in other conditions (e.g. stress) [45-47]. BDNF and $\operatorname{TrkB}$ suppression in the present study differs from the absence of a similar effect following a single episode of moderate hypoglycemia in rats of comparable age [14]. A similarly disparate pattern has been demonstrated with

Recurrent Hypoglycemia and the Prefrontal Cortex

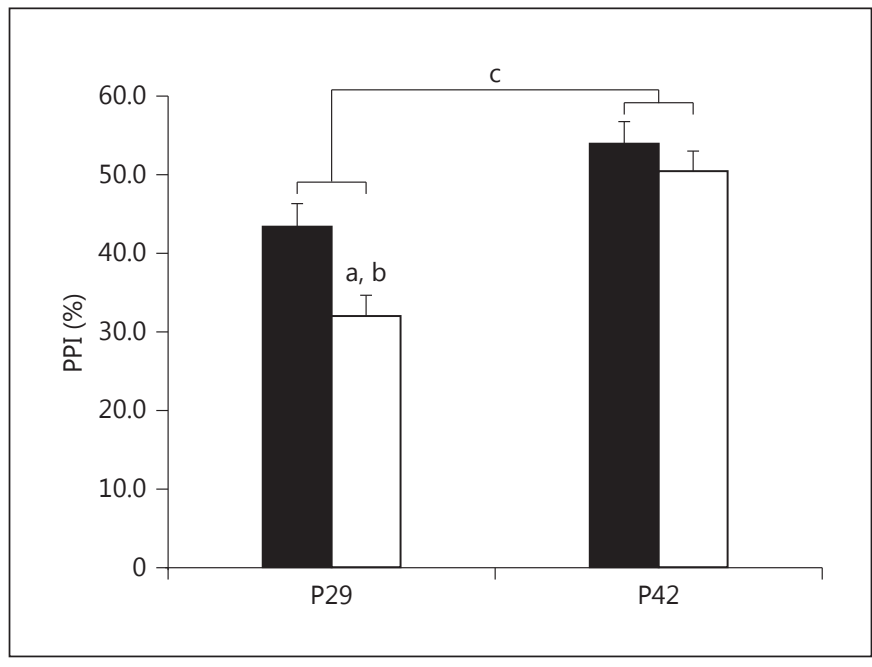

Fig. 3. Acute and long-term effects of recurrent hypoglycemia on PPI of acoustic stimulus in young rats. Three-week-old male rats were subjected to insulin-induced moderate hypoglycemia once daily from P24 to P28. Littermates in the control group were injected with equal volumes of normal saline. PPI was tested $24 \mathrm{~h}$ (on P29) and 2 weeks (on P42) after hypoglycemia. Black bars = Control group; white bars $=\mathrm{RH}$ group. Values are means $\pm \mathrm{SEM}(\mathrm{n}=$ 16). There were significant main effects of group, age at test and group $\times$ age interaction $\left(\mathrm{p}<0.05\right.$ for each; ANOVA). ${ }^{\mathrm{a}} \mathrm{p}<0.05 \mathrm{vs.}$ P29 control group; ${ }^{\mathrm{b}} \mathrm{p}<0.05$ vs. both $\mathrm{P} 42$ control group and $\mathrm{P} 42$ RH group (Tukey's HSD tests); ${ }^{c} \mathrm{p}<0.05, \mathrm{P} 29$ vs. P42 (ANOVA).

postnatal hypoxia in mice, where exposure to a single day of hypoxia does not alter BDNF expression in the PFC, while exposure to recurrent (3-10 days) hypoxia leads to progressive BDNF suppression in the region [21]. Thus, BDNF and TrkB suppression probably reflects the cumulative effect of recurrent hypoglycemia in the present study. The downregulation of Egr1, Egr2, Hmgcr, Pfn 1 and $P f n 2$ transcripts suggests that $\mathrm{BDNF} / \mathrm{TrkB}$ signaling may also be suppressed in the posthypoglycemic period [48]. However, this possibility remains speculative in the absence of a confirmatory protein assay or histochemical analysis. It is noteworthy that recurrent moderate hypoglycemia leads to dampening of PFC activation in the posthypoglycemic period in adult rats $[49,50]$.

The observed functional effects paralleled the BDNF/ TrkB changes in the PFC. Decreased PPI on P29 suggests impaired sensorimotor gating in the posthypoglycemic period. This finding differs from the intact PPI reported in a previous study of recurrent hypoglycemia in younger rats [10]. Differences in the timing of hypoglycemia in the two studies may explain the discrepant results. Recurrent hypoglycemia occurred during the period of 
peak PFC development (P24-P30) [12] in the present study, whereas hypoglycemic episodes (from P9 to P20) had ceased prior to this period in the study by Moore et al. [10]. Lower BDNF/TrkB expression in the PFC may explain the impaired PPI in the present study. PPI is lower in BDNF heterozygous mice that have $40-50 \%$ lower BDNF expression in the frontal cortex than the wild-type mice $[24,25]$. Intracerebral BDNF administration rapidly normalizes PPI deficits in DBA/2J mice [26]. Decreased or disrupted glutamatergic and GABAergic neurotransmission in the PFC may also have had a role in the lower PPI in the present study [27]. Glutamate and GABA concentrations decrease in the brain during hypoglycemia and the depleted concentrations are not restored to the prehypoglycemic levels after the termination of hypoglycemia [42, 43]. Additionally, along with the medial PFC, the hippocampus, nucleus accumbens, amygdala and pontine tegmental area regulate PPI [23]. Although we did not find FJB-stained cells in these brain negatively influenced PPI. Finally, hypoglycemia is a potent stressor and leads to robust corticosterone response in 3-week-old rats [51]. Early life stress negatively influences regional gene expression and behavioral performance, and is known to suppress BDNF expression in the PFC [52-55]. Future studies are necessary to address all these possibilities.

PPI had normalized in the $\mathrm{RH}$ group on $\mathrm{P} 42$. As we did not repeat the test between P29 and P42, it is not possible to know how rapidly PPI normalized following the cessation of hypoglycemia. PPI on P42 was stronger than on P29 in both groups, which is consistent with normal development [56]. Antecedent hypoglycemia also did not affect fear conditioning at adulthood, suggesting intact functional integrity of the PFC, dorsal hippocampus and amygdala by this time point and ruling out new-onset behavioral deficits beyond $\mathrm{P} 42$. BDNF and TrkB $\mathrm{FL}_{\mathrm{FL}}$ expression had also normalized at adulthood. Although TrkB ${ }_{\mathrm{TR}}$ protein expression was upregulated, its functional relevance is unclear. It has been postulated that $\operatorname{TrkB}_{\mathrm{TR}}$ upregulation may negatively modulate TrkB kinase activity by forming TrkB heterodimers [57]. Such an effect is unlikely in the present study, since the expression of downstream targets of BDNF/TrkB signaling were not affected. The absence of long-term behavioral deficits in the present study is similar to the data from adult rats [58]. This is not surprising given that 3 -week-old rats and adult rats have comparable vulnerability to hypoglycemia-induced brain injury $[7,14]$. It is possible that testing under hypoglycemic conditions [59] or testing for more complex regions, we cannot rule out subtle injury that may have

cognitive or affective behaviors [10] would have uncovered additional functional deficits.

In summary, recurrent hypoglycemia during the rapid phase of PFC development led to neuronal injury and suppressed BDNF and TrkB expression in the region and impaired sensorimotor gating in 3-week-old rats. Although these were short-term effects, they were seen after a relatively small number of moderately severe and shortduration episodes of hypoglycemia. From the clinical perspective, the functional deficits in the present study parallel the functional deficits observed in the posthypoglycemic period in children with type 1 diabetes [5]. Even though these functional impairments are transient, typically lasting less than $24 \mathrm{~h}[5,60]$, they interfere with the ability to learn efficiently and have important academic and social implications for the child [61]. The potential for injury and functional deficits suggests the importance of preserving brain energy metabolism using alternative substrates during insulin therapy [14] and exploring novel neuroprotective strategies in this population, such as enhancing BDNF levels through physical activity [62].

\section{Acknowledgments}

The authors acknowledge Bruce Kennedy of the Graduate Program in Neuroscience at the University of Minnesota for his assistance with the behavioral data analysis. This study was funded by the NIH/NICHD (HD47276) and the Viking Children's Fund, Department of Pediatrics, University of Minnesota.

\section{Disclosure Statement}

The authors have no conflicts of interest to declare.
References

\footnotetext{
1 Rao R, Hershey T: The impact of hypoglycemia on the developing brain; in Seaquist ER, Robertson PR (eds): Translational Endocrinology and Metabolism: Hypoglycemia in $\mathrm{Di}$ abetes Update. Chevy Chase, Endocrine Society, 2012, vol 3, pp 137-159.

-2 Stenninger E, Flink R, Eriksson B, Sahlen C: Long-term neurological dysfunction and neonatal hypoglycaemia after diabetic pregnancy. Arch Dis Child Fetal Neonatal Ed 1998;79:F174-F179.

- 3 Hershey T, Perantie DC, Warren SL, Zimmerman EC, Sadler M, White NH: Frequency and timing of severe hypoglycemia affects spatial memory in children with type 1 diabetes. Diabetes Care 2005;28:2372-2377.
} 
-4 Blasetti A, Chiuri RM, Tocco AM, Di Giulio C, Mattei PA, Ballone E, Chiarelli F, Verrotti A: The effect of recurrent severe hypoglycemia on cognitive performance in children with type 1 diabetes: a meta-analysis. J Child Neurol 2011;26:1383-1391.

5 Reich JN, Kaspar JC, Puczynski MS, Puczynski S, Cleland JW, Dell'Angela K, Emanuele MA: Effect of a hypoglycemic episode on neuropsychological functioning in diabetic children. J Clin Exp Neuropsychol 1990;12:613626.

6 Topitsch D, Schober E, Wurst E, KryspinExner I: Changes in attention with hypo- and hyperglycaemia in children with insulin dependent diabetes mellitus. Eur J Pediatr 1998; 157:802-805.

7 Ennis K, Tran PV, Seaquist ER, Rao R: Postnatal age influences hypoglycemia-induced neuronal injury in the rat brain. Brain Res 2008;1224:119-126.

8 Rao R, Sperr D, Ennis K, Tran P: Postnatal age influences hypoglycemia-induced poly(ADP-ribose) polymerase-1 activation in the brain regions of rats. Pediatr Res 2009; 66:642-647.

-9 Yamada KA, Rensing N, Izumi Y, De Erausquin GA, Gazit V, Dorsey DA, Herrera DG: Repetitive hypoglycemia in young rats impairs hippocampal long-term potentiation. Pediatr Res 2004;55:372-379.

10 Moore H, Craft TK, Grimaldi LM, Babic B, Brunelli SA, Vannucci SJ: Moderate recurrent hypoglycemia during early development leads to persistent changes in affective behavior in the rat. Brain Behav Immun 2010;24: 839-849.

11 Rice D, Barone S Jr: Critical periods of vulnerability for the developing nervous system: evidence from humans and animal models. Environ Health Perspect 2000;108(suppl 3):511533.

12 Van Eden CG, Uylings HB: Postnatal volumetric development of the prefrontal cortex in the rat. J Comp Neurol 1985;241:268-274.

13 Nehlig A: Cerebral energy metabolism, glucose transport and blood flow: changes with maturation and adaptation to hypoglycaemia. Diabetes Metab 1997;23:18-29.

14 Ennis K, Dotterman H, Stein A, Rao R: Hyperglycemia accentuates and ketonemia attenuates hypoglycemia-induced neuronal injury in the developing rat brain. Pediatr Res 2015;77:84-90.

15 Nehlig A, Pereira de Vasconcelos A: Glucose and ketone body utilization by the brain of neonatal rats. Prog Neurobiol 1993;40:163221.

16 McAllister AK: Neurotrophins and cortical development. Results Probl Cell Differ 2002; 39:89-112.

17 Pandya CD, Pillai A: TrkB interacts with ErbB4 and regulates NRG1-induced NR2B phosphorylation in cortical neurons before synaptogenesis. Cell Commun Signal 2014; 12:47.
18 Ninan I: Synaptic regulation of affective behaviors; role of BDNF. Neuropharmacology 2014;76(pt C):684-695.

19 Aid T, Kazantseva A, Piirsoo M, Palm K, Timmusk T: Mouse and rat BDNF gene structure and expression revisited. J Neurosci Res 2007; 85:525-535.

20 Huang EJ, Reichardt LF: Trk receptors: roles in neuronal signal transduction. Ann Rev Biochem 2003;72:609-642.

21 Tian X, Hua F, Sandhu HK, Chao D, Balboni G, Salvadori S, He X, Xia Y: Effect of deltaopioid receptor activation on BDNF-TrkB vs. TNF- $\alpha$ in the mouse cortex exposed to prolonged hypoxia. Int J Mol Sci 2013;14:1595915976.

22 von Arnim CA, Hellweg R, Buchner M, Huber R, Riepe MW: Regional selectivity of amyloid mRNA expression and neurotrophins on repetitive inhibition of oxidative phosphorylation. J Neural Transm 2005;112:491-498.

23 Swerdlow NR, Geyer MA, Braff DL: Neural circuit regulation of prepulse inhibition of startle in the rat: current knowledge and future challenges. Psychopharmacology (Berl) 2001;156:194-215.

24 Hill RA, van den Buuse M: Sex-dependent and region-specific changes in TrkB signaling in BDNF heterozygous mice. Brain Res 2011; 1384:51-60.

25 Manning EE, van den Buuse M: BDNF deficiency and young-adult methamphetamine induce sex-specific effects on prepulse inhibition regulation. Front Cell Neurosci 2013;7: 92.

26 Naumenko VS, Bazovkina DV, Morozova MV, Popova NK: Effects of brain-derived and glial cell line-derived neurotrophic factors on startle response and disrupted prepulse inhibition in mice of DBA/2J inbred strain. Neurosci Lett 2013;550:115-118.

-27 Grottick AJ, Bagnol D, Phillips S, McDonald J, Behan DP, Chalmers DT, Hakak Y: Neurotransmission- and cellular stress-related gene expression associated with prepulse inhibition in mice. Brain Res Mol Brain Res 2005; 139:153-162.

28 Burman MA, Gewirtz JC: Timing of fear expression in trace and delay conditioning measured by fear-potentiated startle in rats. Learn Mem 2004;11:205-212.

29 Chavez-Valdez R, Martin LJ, Razdan S, Gauda EB, Northington FJ: Sexual dimorphism in BDNF signaling after neonatal hypoxia-ischemia and treatment with necrostatin-1. Neuroscience 2014;260:106-119.

-30 Lehmann AE, Ennis K, Georgieff MK, Rao R, Tran PV: Evidence for a hyporesponsive limbic-hypothalamic-pituitary-adrenal axis following early-life repetitive hypoglycemia in adult male rats. Am J Physiol Regul Integr Comp Physiol 2011;301:R484-R490.

31 Lucas A, Morley R, Cole TJ: Adverse neurodevelopmental outcome of moderate neonatal hypoglycaemia. BMJ 1988;297:1304-1308.
32 Duvanel CB, Fawer CL, Cotting J, Hohlfeld P, Matthieu JM: Long-term effects of neonatal hypoglycemia on brain growth and psychomotor development in small-for-gestationalage preterm infants. J Pediatr 1999;134:492498.

33 Langan SJ, Deary IJ, Hepburn DA, Frier BM: Cumulative cognitive impairment following recurrent severe hypoglycaemia in adult patients with insulin-treated diabetes mellitus. Diabetologia 1991;34:337-344.

34 Pisansky MT, Wickham RJ, Su J, Fretham S, Yuan LL, Sun M, Gewirtz JC, Georgieff MK: Iron deficiency with or without anemia impairs prepulse inhibition of the startle reflex. Hippocampus 2013;23:952-962

35 Gewirtz JC, Davis M: Habituation of prepulse inhibition of the startle reflex using an auditory prepulse close to background noise. Behav Neurosci 1995;109:388-395.

-36 Alder J, Thakker-Varia S, Bangasser DA, Kuroiwa M, Plummer MR, Shors TJ, Black IB: Brain-derived neurotrophic factor-induced gene expression reveals novel actions of VGF in hippocampal synaptic plasticity. J Neurosci 2003;23:10800-10808.

37 DeSteno DA, Schmauss C: Induction of early growth response gene 2 expression in the forebrain of mice performing an attentionset-shifting task. Neuroscience 2008;152: 417-428.

38 Murk K, Wittenmayer N, MichaelsenPreusse K, Dresbach T, Schoenenberger CA, Korte M, Jockusch BM, Rothkegel M: Neuronal profilin isoforms are addressed by different signalling pathways. PLoS One 2012;7: e34167.

-39 Tkacs NC, Pan Y, Raghupathi R, DunnMeynell AA, Levin BE: Cortical Fluoro-Jade staining and blunted adrenomedullary response to hypoglycemia after noncoma hypoglycemia in rats. J Cereb Blood Flow Metab 2005;25:1645-1655.

40 Teves D, Videen TO, Cryer PE, Powers WJ: Activation of human medial prefrontal cortex during autonomic responses to hypoglycemia. Proc Natl Acad Sci USA 2004;101:62176221.

41 Teh MM, Dunn JT, Choudhary P, Samarasinghe Y, Macdonald I, O'Doherty M, Marsden P, Reed LJ, Amiel SA: Evolution and resolution of human brain perfusion responses to the stress of induced hypoglycemia. Neuroimage 2010;53:584-592.

42 Rao R, Ennis K, Long JD, Ugurbil K, Gruetter $R$, Tkac I: Neurochemical changes in the developing rat hippocampus during prolonged hypoglycemia. J Neurochem 2010;114:728738.

43 Sutherland GR, Tyson RL, Auer RN: Truncation of the Krebs cycle during hypoglycemic coma. Med Chem 2008;4:379-385.

44 Jiang L, Herzog RI, Mason GF, de Graaf RA, Rothman DL, Sherwin RS, Behar KL: Recurrent antecedent hypoglycemia alters neuronal oxidative metabolism in vivo. Diabetes 2009; 58:1266-1274
Recurrent Hypoglycemia and the Prefrontal Cortex
Dev Neurosci 2016;38:74-82 DOI: $10.1159 / 000442878$ 
45 Dragunow M, Hughes P, Mason-Parker SE, Lawlor P, Abraham WC: TrkB expression in dentate granule cells is associated with a late phase of long-term potentiation. Brain Res Mol Brain Res 1997;46:274-280.

46 Castren E, da Penha Berzaghi M, Lindholm D, Thoenen H: Differential effects of MK-801 on brain-derived neurotrophic factor mRNA levels in different regions of the rat brain. Exp Neurol 1993;122:244-252.

$\checkmark 47$ Greenwood BN, Strong PV, Foley TE, Thompson RS, Fleshner M: Learned helplessness is independent of levels of brain-derived neurotrophic factor in the hippocampus. Neuroscience 2007;144:1193-1208.

- 48 Tran PV, Fretham SJ, Carlson ES, Georgieff MK: Long-term reduction of hippocampal brain-derived neurotrophic factor activity after fetal-neonatal iron deficiency in adult rats. Pediatr Res 2009;65:493-498.

49 Hurst P, Garfield AS, Marrow C, Heisler LK, Evans ML: Recurrent hypoglycemia is associated with loss of activation in rat brain cingulate cortex. Endocrinology 2012;153:19081914.

-50 Jahagirdar V, Ramcharitar J, Cotero VE, McNay EC: Moderate recurrent hypoglycemia markedly impairs set-shifting ability in a rodent model: cognitive and neurochemical effects. Open Diabetes J 2012;5:1-7.
51 Rao R: Hypothalamic-pituitary-adrenal axis programming after recurrent hypoglycemia during development. J Clin Med 2015;4: 1729-1740.

-52 Cohen JL, Glover ME, Pugh PC, Fant AD, Simmons RK, Akil H, Kerman IA, Clinton SM: Maternal style selectively shapes amygdalar development and social behavior in rats genetically prone to high anxiety. Dev Neurosci 2015;37:203-214.

53 Kleiber ML, Laufer BI, Stringer RL, Singh SM: Third trimester-equivalent ethanol exposure is characterized by an acute cellular stress response and an ontogenetic disruption of genes critical for synaptic establishment and function in mice. Dev Neurosci 2014;36:499_ 519.

54 Blaze J, Scheuing L, Roth TL: Differential methylation of genes in the medial prefrontal cortex of developing and adult rats following exposure to maltreatment or nurturing care during infancy. Dev Neurosci 2013;35:306316.

55 Gourley SL, Kedves AT, Olausson P, Taylor JR: A history of corticosterone exposure regulates fear extinction and cortical NR2B, GluR2/3, and BDNF. Neuropsychopharmacology 2009;34:707-716.

56 Lipska BK, Swerdlow NR, Geyer MA, Jaskiw GE, Braff DL, Weinberger DR: Neonatal excitotoxic hippocampal damage in rats causes post-pubertal changes in prepulse inhibition of startle and its disruption by apomorphine. Psychopharmacology (Berl) 1995;122:35-43.
57 Merlio JP, Ernfors P, Kokaia Z, Middlemas DS, Bengzon J, Kokaia M, Smith ML, Siesjo BK, Hunter T, Lindvall O, et al: Increased production of the TrkB protein tyrosine kinase receptor after brain insults. Neuron 1993;10: 151-164.

58 McNay EC, Williamson A, McCrimmon RJ, Sherwin RS: Cognitive and neural hippocampal effects of long-term moderate recurrent hypoglycemia. Diabetes 2006;55:1088-1095.

59 McNay EC, Sherwin RS: Effect of recurrent hypoglycemia on spatial cognition and cognitive metabolism in normal and diabetic rats. Diabetes 2004;53:418-425.

60 Bischoff LG, Warzak WJ, Maguire KB, Corley KP: Acute and chronic effects of hypoglycemia on cognitive and psychomotor performance. Nebr Med J 1992;77:253-262.

61 Northam EA, Rankins D, Cameron FJ: Therapy insight: the impact of type 1 diabetes on brain development and function. Nat Clin Pract Neurol 2006;2:78-86.

62 Tonoli C, Heyman E, Roelands B, Buyse L, Piacentini F, Berthoin S, Bailey S, Pattyn N, Meeusen R: BDNF, IGF-I, glucose and insulin during continuous and interval exercise in type 1 diabetes. Int J Sports Med 2015;36:955959. 